\title{
Public Perception of Physical Risks: Effect of the Experience of Repeated Explosion Accidents at a Chemical Plant
}

\author{
Yusuke Koshiba ${ }^{*}$, Hideo Ohtani ${ }^{2}$ \\ ${ }^{1}$ Department of Materials Science and Chemical Engineering, Yokohama National University, Yokohama, Japan \\ ${ }^{2}$ Department of Safety Management, Yokohama National University, Yokohama, Japan \\ Email: ${ }^{*}$ kkoshiba@ynu.ac.jp
}

Received 3 April 2015; accepted 11 June 2015; published 15 June 2015

Copyright (C) 2015 by authors and Scientific Research Publishing Inc.

This work is licensed under the Creative Commons Attribution International License (CC BY).

http://creativecommons.org/licenses/by/4.0/

(c) (i) Open Access

\begin{abstract}
To explore the influence of experiencing accidental explosions, a questionnaire-based survey was conducted. This paper compares the risk perception characteristics of inhabitants living near a chemical plant at which accidental explosions occurred (group A) and of those living near a plant where no serious accidents have occurred (group B). The survey forms contain the following items: demographics, knowledge about causes of accidental explosion, dread, frequency, and risk rating variables. In addition, participants of group $A$ are asked about their level of participation in physical risk communication. The survey reveals that 1) participants of group $A$ have a greater sense of dread than those of group B; 2) participants of group A are more likely to perceive accidental explosions in chemical plants that occur more frequently; 3) risk rating of physical risks is independent of that of health risks; 4) the "frequency" variable is a key factor that influences decision making whether they participate in physical risk communication or not.
\end{abstract}

\section{Keywords}

Physical Risk, Explosion Accident, Risk Perception, Experience, Chemical Plant

\section{Introduction}

Physical risk is the risk of death, injury and property damage caused by a physical effect (e.g., explosion, fire, radiant heat, projection) [1]. Industrial accidents involving hazardous materials can result from explosions, fires, chemical spills and leaks, leading to human injury and environmental damage. Industrial accidents may cause both casualties and economic loss; thus, accidental explosions and fires at a chemical plant pose a social prob-

"Corresponding author.

How to cite this paper: Koshiba, Y. and Ohtani, H. (2015) Public Perception of Physical Risks: Effect of the Experience of Repeated Explosion Accidents at a Chemical Plant. Open Journal of Safety Science and Technology, 5, 45-54.

http://dx.doi.org/10.4236/ojsst.2015.52006 
lem in many countries [2]-[5]. Predictably, any industrial plant dealing with hazardous materials poses a physical risk. In Japan, explosion and fire accidents involving dangerous goods have increased over the previous two decades (1994-2011) [6]. In particular, serious accidental explosions and fires have received much attention owing to the fact that such accidents tend to be highly publicized. Further, the social and political impacts of accidental explosions and fires are often intensified by public perception of risks [7]. Previously, many risk perception studies have focused on natural hazards [8], and health and environmental problems [9]. Reportedly, the experience of a hazard has a greater effect on risk perception and risk-related behavior [8]. The effect of the experience of a hazard event on risk perceptions may vary depending on the type of risk event or activity involved. However, few studies have been reported on the effects of the experience of a physical hazard. Thus, the development of effective risk management and communication about physical risks requires an understanding of the public's perception of physical risk.

In the present study, we compare the risk perception of people living near a chemical plant at which accidental explosions/fires occurred and that of people living near a chemical plant where no other serious explosion/fire accidents happened nearby. This study employed a questionnaire survey to investigate the influence of the direct explosion experience. Risk perception of the two groups is characterized by five parameters: demographics, knowledge about causes of accidental explosions, dread, frequency of accidents, and risk rating variables. The reasons why these parameters are employed in this study are as follows. Demographic variables have been found to be an important predictor of risk perception [10]. Many studies on risk perception have suggested that "dread" is the most important factor [11] [12]. In this study, because a majority of people living near a chemical plant have twice experienced accidental explosions of the chemical plant, "frequency" is included as a variable. In addition, these people who live near a chemical plant where accidental explosions/fires occurred are asked whether they want to participate in physical risk communication.

\section{Accident Description}

Yokohama is the second largest city in Japan by population and an important industrial city in the Keihin industrial region (Figure 1). Yokohama's major industries include petrochemical and other chemicals, automobiles, and machinery. While many facilities are located in lightly populated areas, some chemical plants manufacturing hazardous materials are located in close proximity to residential areas as well.

On January 7, 2010, 5:47 p.m., a strong explosion caused by a runaway reaction occurred at a chemical plant (hereafter referred to as Plant A) near a residential area [13]. This plant is located in an industrial park in Yokohama city, which borders Tokyo Bay to the east and a residential area to the west. In the residential area, there are several schools and stations. The explosion injured eight operators at the chemical plant and four people outside of it. The blast also damaged roughly 17 buildings at the plant including four that were completely destroyed and three that subsequently burned down. In addition, 82 buildings and 69 cars were damaged outside of

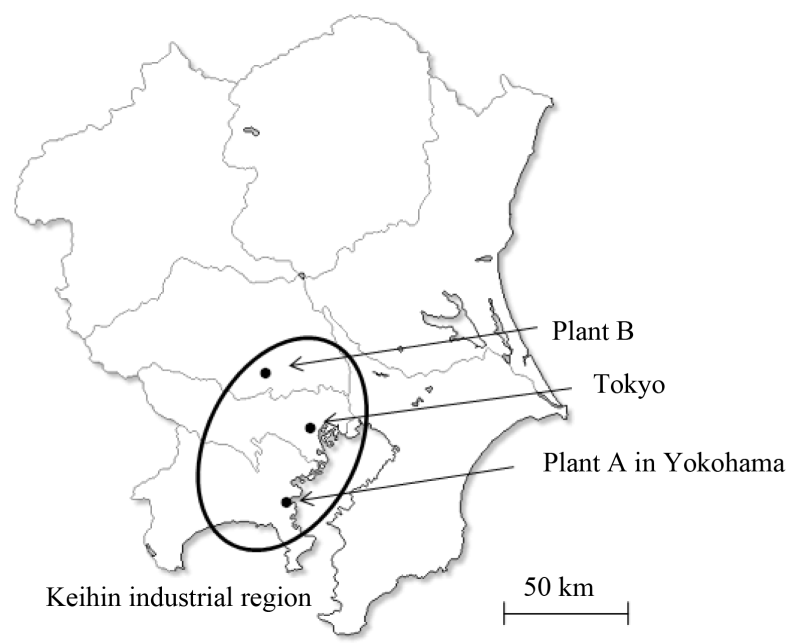

Figure 1. Map of Keihin industrial region. 
the plant. The explosion blasted several pieces of debris: a 10-ton autoclave used as a reactor vessel, a stirring motor, and a part of the autoclave were found $38 \mathrm{~m}, 48 \mathrm{~m}$, and $739 \mathrm{~m}$ away from the plant, respectively. Newspapers reported that many nearby inhabitants heard a huge blast and witnessed fireball, smoke plume, and flying debris.

Another explosion accident occurred at the same chemical plant A on April 7, 2008 [13]. This explosion caused one death and one injury. A fire triggered by this explosion burned down one building and damaged others. To be precise, two huge accidental explosions have occurred at this chemical plant A in a short period. Hence, when an explosion occurred in 2010, the event was highly publicized by local media.

\section{Methods}

\subsection{Participants and Data Collection}

The main objective of this study is to elucidate how the experiences of explosion accidents influence risk perception characteristics. Perceived risk can be directly affected by the experiences of repeated explosion and fire accidents. In this paper, we surveyed the differences in the perceived physical risk between inhabitants living near plant $\mathrm{A}$ and those living near a chemical plant manufacturing similar hazardous materials but where no serious industrial accident has occurred (hereafter referred to as Plant B).

Because one piece of debris, which was believed to be a part of the autoclave, was discovered approximately $740 \mathrm{~m}$ away by the blasts, a total of 52 adult inhabitants ( 29 males and 23 females, see Table 1) who lived within $700 \mathrm{~m}$ from plant A (hereafter referred to as group A) were randomly sampled. All the participants were interviewed using a face-to-face interview to achieve a high response rate and to provide assistance in answering. The survey was completed from January 2010 to February 2010, and all subjects were unpaid. Note that no industrial accident occurred at the area during the survey.

Aside from this survey, face-to-face interviews were conducted with 87 inhabitants (group B: 43 males and 44 females) who lived near plant B from February 2010 to March 2010 employing the same method as group A. The chemical plant $B$ is also located in the Keihin industrial region. As mentioned above, no serious fire/explosion incident had occurred at plant B for a long period. Plant B was selected as it was in the same industry (hazardous material manufacture) and had nearly equal staffing and site area. However, there may be slight differences in their safety management system and the amount of chemicals stored and used. Although a simple comparison is not accurate, we do not address this problem here because this study focuses simply on the impact of repeated industrial accidents such as explosion and fire on risk perception.

\subsection{Instrument}

In the questionnaire, the participants had to answer utilizing five-point scales, yes/no, multiple choice, and open response. The questionnaire included 11 questions and took approximately eight minutes to complete.

The participants were asked two basic demographic questions: gender and age. In general, various perceived

Table 1. Demographic data of participants (group A: $n=52$; group B: $n=87$ ).

\begin{tabular}{ccc}
\hline Variables & Group A & Group B \\
\cline { 2 - 3 } Gender & \multicolumn{2}{c}{ Number of respondents, n (\%) } \\
Male & $29(55.8 \%)$ & $43(49.4 \%)$ \\
Female & $23(44.2 \%)$ & $44(50.6 \%)$ \\
Experience & & $44(50.6 \%)$ \\
Yes & $47(90.4 \%)$ & $43(49.4 \%)$ \\
No & $5(9.6 \%)$ & - \\
Relationship & & - \\
Yes & $8(15.4 \%)$ & - \\
No & $44(84.6 \%)$ & \\
\hline
\end{tabular}


risks (e.g., health risk) are influenced by age [14]. Perhaps the variable affects the explanatory variables. Unfortunately, this study cannot use the date of the age variable because there were a number of missing values. Group A was asked about the experience as follows: "Have you ever heard, felt, or seen fire and/or explosion at chemical plant A?" On the other hand, the question to group B was "Have you ever heard, felt, or seen fire and/or explosion at a chemical plant in Japan?” The next question for group A was about the relationship between the respondents (or their family) and the industrial park including chemical plant A: "Do/Did you have someone who works/worked at the industry park in your household or family?” The respondents had to choose 1) Yes (self/family member) or 2) No. Those who directly benefit from the industry park (i.e., themselves or their family member employed in the industry park) tend to understand risks involved [15] to characterize risks in terms of probability [16] or to rate risks as low [17]. The relationship, in any case, can significantly affect the explanatory variables.

The next question asked about the specific knowledge of the cause of fire/explosion accidents. The question to group A was "Do you know the cause of the fire/explosion accident at the chemical plant A?", and the question to group B was "Do you know the cause of the fire/explosion accident at a chemical plant in Japan?".

Participants were then asked about dread and frequency on five-point scales: "How much do you dread the physical hazard from chemical plants?", and "How likely do you think fire/explosion accidents at chemical plants in Japan are occurring a year ranging from 1 (not at all) to 5 (very often)?”.

The next questions asked were about rating the size of the physical risk related to the physical hazard compared with that related to other hazards such as nuclear power, typhoon, earthquake, genetically modified foods (GMO), new influenza, automobiles, airplanes, and health problems resulting from drinking alcohol and smoking. The first five hazards can be considered to be involuntary risk activities, whereas the others are voluntary risk activities. The reason for selecting these hazards is that all of them are usually present in Japan. In particular, the 2009 flu pandemic caused approximately 200 deaths in Japan [18]. Such a comparison makes it possible to measure the relative magnitude of perceived risk associated with physical hazards.

Finally, the participants were asked whether to participate in physical risk communication. When the participant responded yes, the desire for additional information in physical risk communication was evaluated by multiple-choice questions.

\subsection{Quantification Method Type II}

Hayashi's quantification method type II (hereafter referred to as quantification method II) [19] [20] is a linear discriminant analysis for categorical data. This method pairs a categorical variable with a dummy variable (i.e., 0 or 1), allowing the analysis of a quantitative relationship between an objective variable and an explanatory variable. The quantification method type II has been used to quantitatively analyze categorical data in a number of studies. For instance, Ju and Sohn analyzed injury phenomena in traffic accidents [21], and Saito et al. revealed risk factors regarding forest road collapse [22]. In this study, we applied the quantification method II to the data of group A in order to clarify an important factor affecting the level of interest in participating in physical risk communication, i.e., the presence or absence of interest in participation in the risk communication was selected as an objective variable and other variables were employed as explanatory variables.

\section{Results}

Differences were considered to be significant at $p<0.05$ in the statistical analyses. An economical relationship with the industrial park (i.e., the participants themselves or their households who worked at the industrial park) is shown in Table 1. 15.6\% of group A was or had been economically tied to the industrial park. While only $50.6 \%$ of group B had heard and/or saw a fire/explosion accident at chemical plants, a majority (90.4\%) of group A reported that they had felt the fire/explosion at plant A (see Table 1). Fisher's exact test comparing the difference of the proportions revealed that the difference was statistically significant $(p<0.001)$. Of the participants who answered yes to the question, more than one-third (34.0\%) in group A and $40.9 \%$ of group B answered that they knew the accident cause. There were no significant differences in the proportions between groups A and B $(p=0.52)$.

\subsection{Ratings of Dread, Frequency, and Perceived Risk Variables}

The means of rated dread for group A and group B were $\mathrm{M}=4.69(S D=0.46)$ and $\mathrm{M}=3.91(S D=1.18)$, re- 
spectively (see Table 2). $\mathrm{M}$ and $S D$ represent mean value and one standard deviation of the data, respectively. It is important to note that 1 ) in group B, approximately $5 \%$ and $13 \%$ of respondents rated their dread as "Not at all" and "A little" respectively; 2) in contrast, in group A, all the participants indicated that their dread were "Somewhat" (30.8\%) or "Very" (69.2\%, mode). Owing to lack of normality in these data (Kolmogorov-Smirnov test, $p<0.001$ ), the Mann-Whitney $U$ test was applied to nonparametric analysis. The test demonstrated a significant difference in the perception of dread between group A and group B $(p<0.001)$, thereby indicating that participants in group A had a greater sense of dread than those in group B.

The mean value of rated frequency for group $\mathrm{B}$ was $\mathrm{M}=2.57(\mathrm{SD}=0.84)$. In group $\mathrm{B}$, only a few participants answered "Not at all" ( $\mathrm{n}=4,4.5 \%)$. The mode value was found to be "A little" ( $\mathrm{n}=46,52.3 \%)$. On the other hand, in group $\mathrm{A}$, the mean value was $\mathrm{M}=3.04(S D=0.68)$, and no participant rated their frequency as "Not at all." Because the Kolmogorov-Smirnov test showed that the distribution of the data was not normal $(p<0.001)$, the Mann-Whitney $U$ test was used. As a result, the means of frequency rated were significantly different $(p<$ 0.001). This indicated that experienced participants were more likely to perceive fire/explosion accidents in chemical plants as something that will occur more frequently.

Table 3 presents the risk ratings of a variety of hazards by comparing them with the physical risk from chemical plants. When the value is three, the risk rating of the hazard is rated as equivalent to the physical risk. Higher values indicate greater perceived risk ratings than the physical risks. In group A, "Nuclear power," "Typhoon," "Earthquake," "Genetically modified foods (GMO)," and "Airplanes" were perceived as a greater risk activities/event. Conversely, "New influenza," "Automobiles," "Alcohol," and "Smoking” were less fearsome to group A. In group B, the risk ratings of "Nuclear power," "Earthquake," "GMO," and "Airplanes” were higher than three. Because the scale type used was a rank scale, the Mann-Whitney $U$ test was applied to compare the risk ratings, allowing it to roughly divide the nine hazards into three categories: 1) hazards that the physical risk rating relatively increased; 2) hazards that the physical risk rating relatively decreased; and 3) hazards that the physical risk rating remained unchanged after the experience of the accidents. Category 1 included "Nuclear power". That is, the participants of group A tended to rate the physical risk as something smaller than the risk of nuclear power $(p<0.05)$. "Typhoon" and "Earthquake” fell into Category 2. This means that participants of group A tended to perceive the physical risk as greater than the risk of the two natural disasters (Typhoon, $p<$ 0.05; Earthquake, $p<0.001$ ). Category 3 contained "GMO," "New influenza," "Automobiles," "Airplanes," "Alcohol", and "Smoking". These activities/events are hazards for which there are no significant differences in the risk ratings between group A and group B (all $p>0.05$ ). Most of those are health risks. The prominent effect of individuals' experiences of the accidental explosions/fires on their risk judgments was not found: it was possible that the risk rating of physical risk was not strongly associated with that of health risks.

\subsection{Level of Interest in Risk Communication and Desire for Information}

While approximately half of the respondents of group B (51.1\%) were concerned about participation in risk communication of physical risks, a majority of the respondents of group A (80.8\%) did so (see Table 4). There were significant differences in these data between group A and group B (Fisher's exact test, $p<0.001$ ).

Figure 2 showed proportions of group A participants who desired information concerning fire/explosion accidents. A total of $38.5 \%$ of participants wished information on the names and amounts of hazardous chemicals handled at chemical plant A. Those who desired information on an emergency manual were less than $40 \%$. These represented desire for safety information. In contrast, most respondents desired information on frequency of fire/explosion accident (88.5\%), anticipated extent of damage (75.0\%), and riskiness of the plant (67.3\%). This indicated that participants of group A preferred risk information rather than safety information.

Table 2. Means of ratings dread and frequency variables.

\begin{tabular}{ccc} 
& & Mean $(S D)$ \\
& & Frequency \\
\cline { 2 - 3 } Group A & $4.69(0.46)$ & $3.04(0.68)$ \\
Group B & $3.91(1.18)$ & $2.57(0.84)$ \\
$p$ value & $0.000^{* * *}$ & $0.000^{* * *}$ \\
\hline
\end{tabular}

${ }^{*} p<0.05 ;{ }^{* *} p<0.01 ;{ }^{* * *} p<0.001$. 
Table 3. Means of risk ratings.

\begin{tabular}{|c|c|c|c|}
\hline \multirow{2}{*}{ Hazards } & \multicolumn{2}{|c|}{ Mean $(S D)$} & \multirow{2}{*}{$p$ value } \\
\hline & Group A & Group B & \\
\hline Nuclear power & $4.35(1.27)$ & $4.76(0.80)$ & $0.018^{*}$ \\
\hline Typhoon & $3.42(1.47)$ & $2.91(1.22)$ & $0.029^{*}$ \\
\hline Earthquake & $4.49(1.06)$ & 3.04 (1.48) & $0.000^{* * * *}$ \\
\hline Genetically modified foods & 3.09 (1.36) & $3.40(1.57)$ & 0.209 \\
\hline New influenza & $2.91(1.55)$ & $2.55(1.34)$ & 0.197 \\
\hline Automobile & $2.35(1.31)$ & $2.62(1.22)$ & 0.132 \\
\hline Airplane & $3.70(1.49)$ & $4.11(1.36)$ & 0.087 \\
\hline Alcohol & $1.79(1.30)$ & $2.13(1.19)$ & 0.055 \\
\hline Smoking & $2.16(1.63)$ & $2.33(1.30)$ & 0.242 \\
\hline
\end{tabular}

${ }^{*} p<0.05 ;{ }^{* *} p<0.01 ;{ }^{* * *} p<0.001$.

Table 4. Proportions of participants who were concerned about participation in the risk communication.

\begin{tabular}{rrr}
\hline & & Proportion (\%) \\
\hline Group A & 80.8 \\
Group B & 51.1 \\
\hline
\end{tabular}

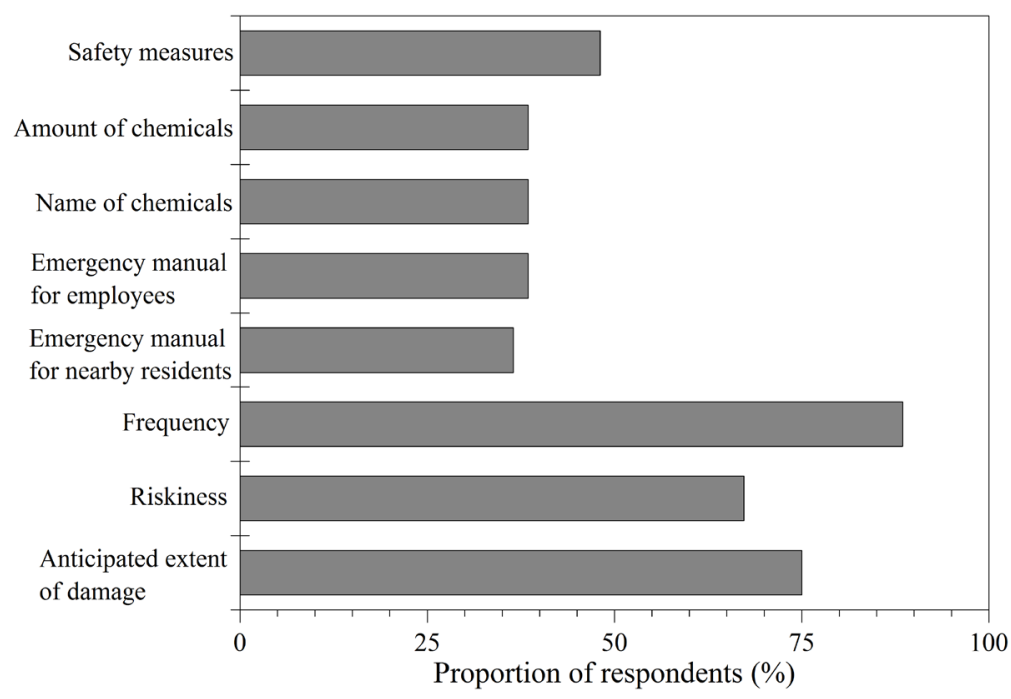

Figure 2. Proportions of participants of group A who desired information concerning fire/explosion accidents.

\subsection{Identification of Factors Affecting the Level of Interest for Risk Communication}

To elucidate an important factor affecting the level of interest in participating in physical risk communication, we applied quantification method II to the data of group A. Because this method required independence among the objective variables, the chi-squared $\left(\chi^{2}\right)$ test was conducted for each objective variable. Because the "Knowledge” variable was not independent of other variables, five variables, i.e., "Gender," "Experience,” "Relationship," "Dread," and "Frequency” were finally determined to be explanatory variables. The results obtained from the $\chi^{2}$ test are summarized in Table 5 (all $p>0.05$ ).

Figure 4 shows the category scores of the three variables. In this figure, the positive category score has a positive effect on the objective variable. Conversely, the negative category score exerts a negative effect, meaning 
Table 5. Results of $\chi^{2}$ test for the explanatory variables.

\begin{tabular}{lccccc}
\hline & 1 & 2 & 3 & 4 & 5 \\
\hline 1. Gender & & $0.976^{\mathrm{a}}$ & 0.111 & 0.963 & $0.457^{\mathrm{a}}$ \\
2. Experience & & 0.316 & $0.423^{\mathrm{a}}$ & $0.774^{\mathrm{a}}$ \\
3. Frequency & & & 0.444 & 0.416 \\
4. Dread & & & & $0.423^{\mathrm{a}}$ \\
5. Relationship & & & &
\end{tabular}

\footnotetext{
a: Yate's continuity correction.
}

that the category score tends to positively correlate with the desire to participate in risk communication. Regarding "Frequency" category scores were in order of "Very (CS $=+0.88)$ ", "Somewhat $(\mathrm{CS}=+0.55)$ " > "Neither nor $(\mathrm{CS}=-0.04)$ " > "A little $(\mathrm{CS}=-0.74)$ " > "Not at all $(\mathrm{CS}=-4.26)$ ", indicating that there was a positive correlation between the "Frequency" variable and the objective variable. That is, respondents who perceived fire/explosion accidents as something that occurred more frequently tended to have an interest in participating in risk communication processes. In addition, those who answered "Not at all" were found to express a very low level of concern. Furthermore, "Relationship" those with an economical relationship with the industrial park (CS $=+0.68$ ) wanted to participate in risk communication. Concerning "Dread" category scores of "Very" and "Somewhat" were +0.18 and -0.43 , respectively. Thus, those who had a greater sense of dread tended to desire participation in risk communication.

\section{Discussion}

Our findings in this study revealed that there were no significant differences between groups A and B in the proportion of respondents who knew the accident cause, notwithstanding the fact that most participants of group A directly experienced the explosion accidents twice in a short period. The experience of a hazard has been considered and identified as an important factor governing people's emotion [23]. Kuhar et al. have also shown that people influenced by disasters tended to seek out information regarding the risk [24]. Conversely, people who have constantly experienced extreme risks are sometimes less concerned [25]. As a result, the participants of groups A and B did not significantly differ in the percent of respondents who knew the accident cause.

Our survey showed that group A tended to rate that likelihood of the accident occurring was more frequent and they were more fearful of it (see Table 2). Ho et al. studied risk perception of victims concerning natural hazards of flood and landslide [26]. This study indicated that people with more disaster experiences had a greater dread of these disasters and rated them as something that occurred more frequently. Although it should be noted that the perceived risk may depend on the type of hazard, the fact agrees well with our results of perception of physical risk. According to the availability heuristic [27], people tend to overestimate the likelihood that an event will occur if they have experienced serious consequence of hazards. Thus, the results of the perception of physical risk in this study can be explained by the availability heuristic.

As shown in Table 3, nuclear power was assigned to Category 1. This meant that the perceived physical risk was relatively amplified; in other words, the risk rating of the nuclear power was relatively reduced. The reason could be that most respondents perceived the likelihood that nuclear accidents would occur to be very low. However, this result is not in agreement with the findings reported by Grasa et al. [17], who reported that the risk ratings of chemical plants at which industrial chemical accidents [28] have occurred were lower than those of nuclear power plants by surveying inhabitants near the plants. This difference was probably due to the difference in the number of experience: most participants of group A experienced the repeated accidents in a short period. Note that our questionnaire survey was conducted before the 2011 Tohoku earthquake [29] that caused the Fukushima Daiichi nuclear disaster [30]. Thus, it is now possible that the risk rating of "Nuclear power" has increased. Table 3 also revealed that Category 2 contained typhoon and earthquake, which meant that the physical risk rating relatively decreased. To put it in another way, the perceived risks of typhoon and earthquake were relatively enhanced. In Japan, these two natural disasters occur very frequently and often cause loss of life and property damage. Although most respondents of group A have undoubtedly experienced the accidental explosions/fires, they also more often have experiences of typhoon and earthquake. Unfortunately, although our sur- 
vey does not elucidate the loss and damage of group A by explosion/fire accidents, the effect on the frequency of the event occurring perhaps resulted in the higher risk rating of the two natural disasters compared with that of an explosion/fire accident in the chemical plant.

As shown in Figure 3, the item range of "Frequency" variable was largest among the five explanatory variables, indicating that it remarkably dominated the objective variable (i.e., level of interest in participating physical risk communication). In addition, as can be seen from Figure 4, participants who witnessed the explosion/fire accidents tended to have an interest more frequently. It is known that greater frequency of involuntary experiences has a positive relationship with greater concern [31]. It was possible that the participants of group A who had experienced an accident twice were strongly concerned about explosion/fire accidents. As a result, the frequency factor governed the objective variable. Interestingly, the item range of "Gender" had a low item range of 0.31. In general, the gender variable was found to play an important role in the perception of health and environmental risks [10]; however, the gender variable hardly influenced the objective variable in the present study. This was probably because there were no significant differences in "Dread" and "Frequency" ratings between

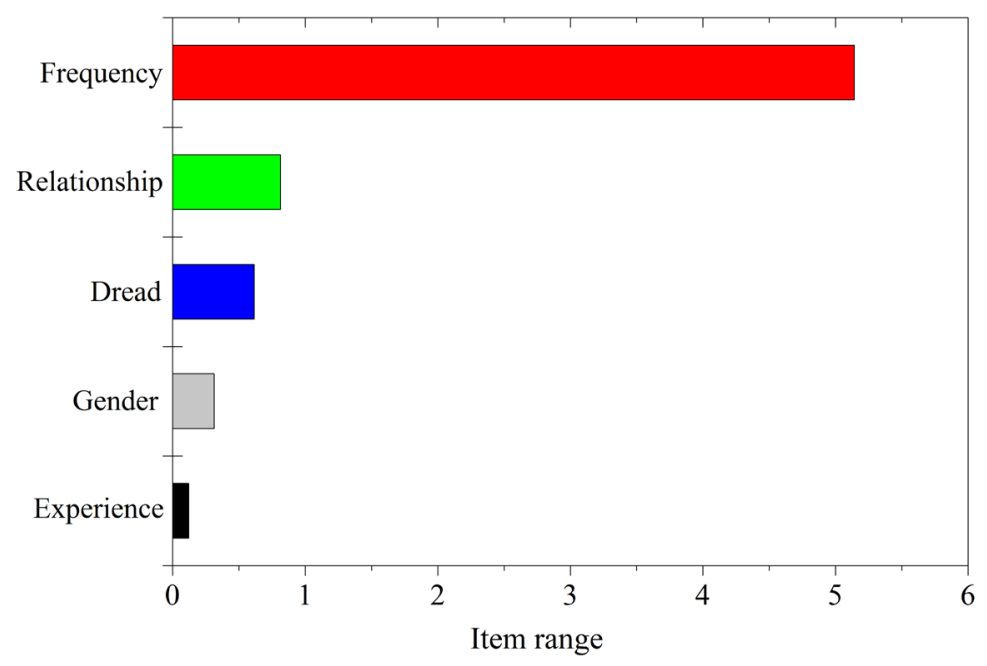

Figure 3. Results of item ranges (IR). As the value of the IR increases, the explanatory variable greatly affects the objective variable.

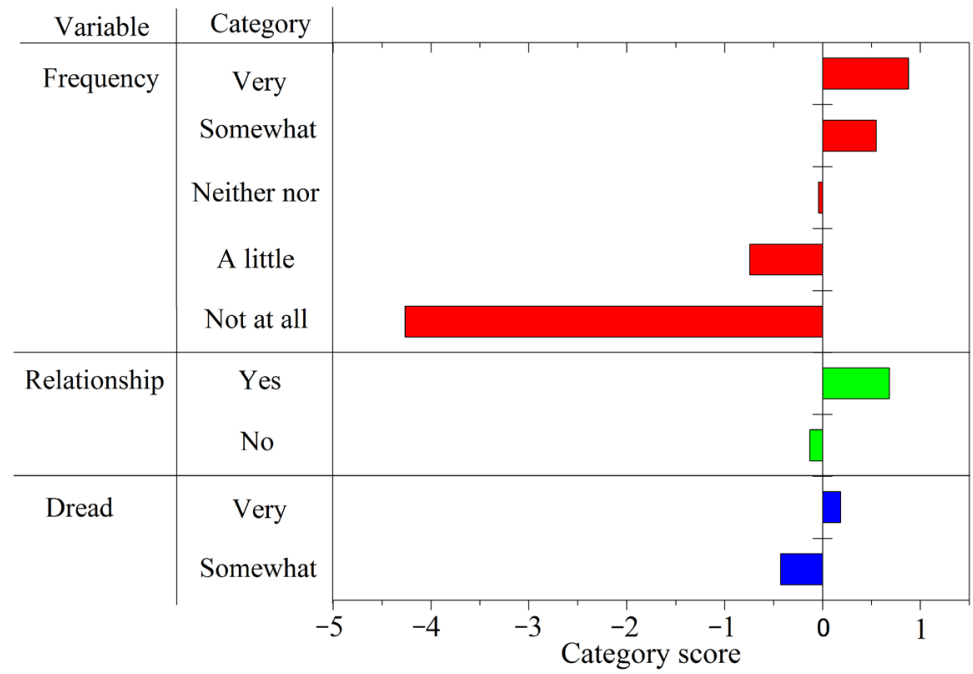

Figure 4. Results of category scores (CS). The positive CS has a positive effect on the objective variable. Conversely, the negative CS exerts a negative effect. 
males and females in group A (Dread: $\mathrm{M}_{\text {male }}=4.96, \mathrm{M}_{\text {female }}=4.70, U$ test, $p=0.96$; Freq.: $\mathrm{M}_{\text {male }}=3.10$, $\mathrm{M}_{\text {female }}=$ 3.00, $U$ test, $p=0.61$ ).

Here some limitations of the present study should be acknowledged. The first limitation is that the questionnaire survey was restricted to inhabitants living near the two chemical plants: plants A and B. The second concerns the relatively small sample size ( $\mathrm{n}=52$ and 87). That said few studies had been reported on perceptions of physical risks; thus, this research provides new insights into the influence of experiencing repeated explosion accidents on the public perception of physical risks. Our findings will be useful for designing effective physical risk communication processes.

\section{Conclusions}

On the basis of the questionnaire survey presented in this paper, the following main conclusions can be obtained:

1) People living near a chemical plant where accidental fires and explosions have previously occurred (group A) have a greater sense of dread than those living near a chemical plant where no fire/explosion accidents have occurred (group B) $\left(\mathrm{M}_{\text {group A }}=4.69, \mathrm{M}_{\text {group B }}=3.91, U\right.$ test, $p<0.001$ ).

2) Participants of group $A$ are more likely to perceive accidental fires and explosions at chemical plants as something that occur more frequently than those of group B $\left(\mathrm{M}_{\text {group A }}=3.04, \mathrm{M}_{\text {group B }}=2.57, U\right.$ test, $\left.p<0.001\right)$.

3) The experience of fire/explosion accidents does not influence risk ratings of health risks such as genetically modified foods, new influenza, health problems resulting from drinking alcohol and smoking. That is, the risk rating of physical risks is probably independent of that of health risks.

4) The experience of accidental fires and explosions remarkably increases the level of interest in participating in physical risk communication (group A: 80.8\%, group B: 51.1\%, Fisher's exact test, $p<0.001$ ).

5) In physical risk communication, a majority of participants of group A requested information concerning the frequency of fire/explosion accidents (88.5\%), extent of damage (75.0\%), and accident risks (67.3\%).

6) Quantification method II reveals that "frequency" is a dominant factor affecting the level of interest in participating physical risk communication. In addition, participants who perceived fire/explosion accidents as something that occurs more frequently tend to show higher levels.

On the basis of the results presented in this study, we conclude that explosion accidents have a marked impact on risk perception characteristics of inhabitants living near a chemical plant at which explosion accidents occurred.

\section{References}

[1] United Nations (2011) Globally Harmonized System of Classification and Labelling of Chemicals. 4th Edition, United Nations Publication, New York and Geneva.

[2] Ettouney, R.S. and EL-Rafai, M.A. (2012) Explosion of Ammonium Nitrate Solutions, Two Case Studies. Process Safety and Environmental Protection, 90, 1-7.

[3] Taveau, J. (2010) Risk Assessment and Land-Use Planning Regulations in France Following the AZF Disaster. Journal of Loss Prevention in the Process Industries, 23, 813-823. http://dx.doi.org/10.1016/j.jlp.2010.04.003

[4] Chen, J.R., Tsai, H.Y., Chen, S.K., Pan, H.R., Hu, S.C., Shen, C.C., Kuan, C.M., Lee, Y.C. and Wu, C.C. (2006) Analysis of a Silane Explosion in a Photovoltaic Fabrication Plant. Process Safety Progress, 25, 237-244. http://dx.doi.org/10.1002/prs.10136

[5] Lacoursiere, J.P. (2005) An Explosion Caused by Mixing Incompatible Liquids. Process Safety Progress, 24, 115-119. http://dx.doi.org/10.1002/prs.10066

[6] Fire and Disaster Management Agency (2012) Dangerous Goods Accidents in 2011. Safety \& Tomorrow, 144, 19-21 (in Japanese).

[7] Burns, W.J. and Slovic, P. (2012) Risk Perception and Behaviors: Anticipating and Responding to Crises. Risk Analysis, 32, 579-582. http://dx.doi.org/10.1111/j.1539-6924.2012.01791.X

[8] Kung, Y.W. and Chen, S.H. (2012) Perception of Earthquake Risk in Taiwan: Effects of Gender and Past Earthquake Experience. Risk Analysis, 32, 1535-1546. http://dx.doi.org/10.1111/j.1539-6924.2011.01760.x

[9] Grasmück, D. and Scholz, R.W. (2005) Risk Perception of Heavy Metal Soil Contamination by High-Exposed and Low-Exposed Inhabitants: The Role of Knowledge and Emotional Concerns. Risk Analysis, 25, 611-622. http://dx.doi.org/10.1111/j.1539-6924.2005.00628.x 
[10] Flynn, J., Slovic, P. and Mertz, C.K. (1994) Gender, Race, and Perception of Environmental Health Risks. Risk Analysis, 14, 1101-1108. http://dx.doi.org/10.1111/j.1539-6924.1994.tb00082.x

[11] Slovic, P. (2000) The Perception of Risk. Earthscan Ltd., Washington DC.

[12] Bronfman, N.C. and Cifuentes, L.A. (2003) Risk Perception in a Developing Country: The Case of Chile. Risk Analysis, 23, 1271-1285. http://dx.doi.org/10.1111/j.0272-4332.2003.00400.x

[13] Aoki, T. (2010) Explosion Accidents at a Chemical Factory in Yokohama. Safety \& Tomorrow, 131, 34-38 (in Japanese).

[14] Armaş, I. (2006) Earthquake Risk Perception in Bucharest, Romania. Risk Analysis, 26, 1223-1234. http://dx.doi.org/10.1111/j.1539-6924.2006.00810.x

[15] Cutchin, M.P., Martin, K.R., Owen, S.V. and Goodwin, J.S. (2008) Concern about Petrochemical Health Risk before and after a Refinery Explosion. Risk Analysis, 28, 589-601. http://dx.doi.org/10.1111/j.1539-6924.2008.01050.x

[16] Sjöberg, L. and Drottz-Sjöberg, B.M. (1991) Knowledge and Risk Perception among Nuclear Power Plant Employees. Risk Analysis, 11, 607-618. http://dx.doi.org/10.1111/j.1539-6924.1991.tb00650.x

[17] Grasa, G., Navarro, V., Rubio, O., Peña, J.A. and Santamaria, J. (2002). A Comparative Study of Risk Perception in Small and Large Communities Where Chemical Industries Are Present. Journal of Loss Prevention in the Process Industries, 15, 525-530. http://dx.doi.org/10.1016/S0950-4230(02)00033-5

[18] Ministry of Health, Labour and Welfare (2010) Information about Influenza A (H1N1) Pdm. http://www.mhlw.go.jp/english/topics/influenza_a/situation_update/dl/100331_the_situation_of_H1N1_in_Japan.pdf

[19] Hayashi, C. (1952) On the Prediction of Phenomena from Qualitative Data and the Quantification of Qualitative Data from the Mathematico-Statistical Point of View. Annals of the Institute of Statistical Mathematics, 3, 69-98. http://dx.doi.org/10.1007/BF02949778

[20] Hayashi, C. (1950) On the Quantification of Qualitative Data from the Mathematico-Statistical Point of View. Annals of the Institute of Statistical Mathematics, 2, 35-47. http://dx.doi.org/10.1007/BF02919500

[21] Ju, Y.H. and Sohn, S.Y. (2011) Quantification Method Analysis of the Relationship between Occupant Injury and Environmental Factors in Traffic Accidents. Accident Analysis and Prevention, 43, 342-351. http://dx.doi.org/10.1016/j.aap.2010.09.002

[22] Saito, M., Shindo, D., Kinoshita, W., Ueki, T. and Inoue, H. (2015) Extraction of Collapse Risk Factors for OperationRoad in Terasawayama. Formath, 14, 60-72. http://dx.doi.org/10.15684/formath.14.007

[23] Richardson, B., Sorensen, J. and Soderstrom, E.J. (1987) Explaining the Social and Psychological Impacts of a Nuclear Power Plant Accident. Journal of Applied Social Psychology, 17, 16-36. http://dx.doi.org/10.1111/j.1559-1816.1987.tb00290.x

[24] Kuhar, S.E., Nierenberg, K., Kirkpatrick, B. and Tobin, G.A. (2009) Public Perceptions of Florida Red Tide Risks. Risk Analysis, 29, 963-969. http://dx.doi.org/10.1111/j.1539-6924.2009.01228.x

[25] MacGregor, D., Slovic, P., Mason, R.G., Detweiler, J., Binney, S.E. and Dodd, B. (1994) Perceived Risks of Radioactive Waste Transport through Oregon: Results of a Statewide Survey. Risk Analysis, 14, 5-14. http://dx.doi.org/10.1111/j.1539-6924.1994.tb00022.x

[26] Ho, M.-C., Shaw, D., Lin, S. and Chiu, Y.-C. (2008) How Do Disaster Characteristics Influence Risk Perception? Risk Analysis, 28, 635-643. http://dx.doi.org/10.1111/j.1539-6924.2008.01040.x

[27] Tversky, A. and Kahneman, D. (1974) Judgment under Uncertainty: Heuristics and Biases. Science, 185, $1124-1131$. http://dx.doi.org/10.1126/science.185.4157.1124

[28] Marco, E., Peña, J.A. and Santamaría, J. (1998) The Chlorine Release at Flix (Spain) on January 21st 1996: A Case Study. Journal of Loss Prevention in the Process Industries, 11, 153-160. http://dx.doi.org/10.1016/S0950-4230(97)00014-4

[29] Japan Meteorological Agency (2011) The 2011 off the Pacific Coast of Tohoku Earthquake—First Report. http://www.jma.go.jp/jma/en/News/2011_Earthquake_01.html

[30] IAEA (2011) Fukushima Nuclear Accident Update Log. http://www.iaea.org/newscenter/news/2011/fukushimafull.html

[31] Barnett, J. and Breakwell, G.M. (2001) Risk Perception and Experience: Hazard Personality Profiles and Individual Differences. Risk Analysis, 21, 171-177. http://dx.doi.org/10.1111/0272-4332.211099 